\title{
Nature, prevalence and factors associated with depression among the elderly in a rural south Indian community
}

\author{
A. P. Rajkumar, ${ }^{1}$ P. Thangadurai, ${ }^{1}$ P. Senthilkumar, ${ }^{1}$ K. Gayathri,, M. Prince ${ }^{2}$ \\ and K. S. Jacob ${ }^{1}$ \\ ${ }^{1}$ Department of Psychiatry, Christian Medical College, Vellore, India \\ ${ }^{2}$ Institute of Psychiatry, London, U.K.
}

ABSTRACT

Background: Depression in old age is an important public health problem causing considerable morbidity and disability worldwide. There is a dearth of community studies from India investigating geriatric depression and its associated risk factors. This study aimed to establish the nature, prevalence and factors associated with geriatric depression in a rural south Indian community.

Methods: We recruited 1000 participants aged over 65 years from Kaniyambadi block, Vellore, India. We assessed their socio-demographic profile, psychiatric morbidity, cognitive functioning, anthropometrics and disability status using the following structured assessment tools: Geriatric Mental State, Community Screening Instrument for Dementia, Modified CERAD 10 word list learning task, History and Aetiology Schedule Dementia Diagnosis and Subtype, WHO Disability Assessment Scale II, and Neuropsychiatric Inventory. We adopted a case control framework to study the factors associated with geriatric depression.

Results: Prevalence of geriatric depression (ICD-10) within the previous one month was $12.7 \%$ (95\% CI 10.64-14.76\%). Low income (OR 1.78; 95\% CI 1.08-2.91), experiencing hunger (OR 2.58; 95\% CI 1.564.26), history of cardiac illnesses (OR 4.75; 95\% CI 1.96-11.52), transient ischemic attack (OR 2.43; 95\% CI 1.17-5.05), past head injury (OR 2.70; 95\% CI 1.36-5.36) and diabetes (OR 2.33; 95\% CI 1.15-4.72) increased the risk for geriatric depression after adjusting for other determinants using conditional logistic regression. Having more confidants (OR 0.13; 95\% CI 0.06-0.26) was the significant protective factor. Age, female gender, cognitive impairment and disability status were not significantly associated with geriatric depression. DSM-IV diagnosis of major depression was significantly correlated with experiencing hunger, diabetes, transient ischemic attack, past head injury, more disability and less nourishment; having more friends was protective.

Conclusions: Geriatric depression is prevalent in rural south India. Poverty and physical ill health are risk factors for depression among elderly while good social support is protective.

Key words: depression, dementia, risk factors, poverty, social supports

\section{Introduction}

Depression is associated with morbidity as well as disability among the elderly (Cole and Dendukuri, 2003). They constitute a major public health problem worldwide and their prevalence rates range between 10 and 55\% (Sherina et al., 2004; Chi et al., 2005; Tsai et al., 2005; Khattri and Nepal, 2006; Kaneko et al., 2007). The long-term prognosis of geriatric depression is bleak with incomplete

Correspondence should be addressed to: K. S. Jacob, Professor of Psychiatry, Christian Medical College, Vellore 632002, India. Phone: +91 416228 4513; Fax: +91 416226 2268. Email: ksjacob@cmcvellore.ac.in. Received 3 Nov 2008; revision requested 3 Dec 2008; revised version received 11 Dec 2008; accepted 15 Dec 2008. recovery (Jhingan et al., 2001) and higher relapse rates (Mitchell and Subramaniam, 2005). Along with the physiological and psychological changes associated with aging, changes in the associated risk factors also modify the prevalence and prognosis of geriatric depression (van't Veer-Tazelaar et al., 2008). Medical co-morbidity (Jongenelis et al., 2004) and cognitive impairment (Steffens and Potter, 2008) have a complex bidirectional relationship with geriatric depression.

Available epidemiological studies on geriatric depression have mostly diagnosed depression by short screening instruments. The low positive predictive value (Arthur et al., 1999) as well as doubtful external validity of screening instruments 
(Kørner et al., 2007) may yield many false positive cases and may inflate the prevalence rates of geriatric depression in community settings. Concerns regarding the different cut-off values used to diagnose depression across various settings also exist (McGivney et al., 1994; Arthur et al., 1999). Many studies have not employed structured assessment of depression, cognitive function and disability (Osborn et al., 2003; Sherina et al., 2004; Chi et al., 2005; Tsai et al., 2005; Khattri and Nepal, 2006; Kaneko et al., 2007). Community studies from India on depression among the elderly are sparse. The only available Indian study employing the Geriatric Depression Scale (GDS), a screening tool, in a small sample of elderly has reported prevalence of up to $45.9 \%$ (Jain and Aras, 2007). Another larger Indian study evaluating the Hindi version of the GDS studied only the depressive symptoms and not the depressive disorders (Ganguli et al., 1999). We aimed to study the nature, prevalence and factors associated with geriatric depression in a rural south Indian community with an adequate sample size and with detailed as well as structured methods of assessment.

\section{Methods}

\section{Study design}

We employed a cross-sectional study to examine the nature and prevalence of geriatric depression in a rural community. We used a case control design framework to identify factors associated with geriatric depression. This study was part of the 10/66 Dementia Research Group population based studies. The methodology employed in this study has been reported elsewhere (Jacob et al., 2007a) and is only briefly mentioned here.

\section{Setting}

Kaniyambadi block of Vellore district is in the southern Indian state of Tamil Nadu. It is spread over 127.4 square kilometers with 85 villages housing a total population of 110,000 . The Department of Community Health, Christian Medical College, Vellore has been running a community health program in this block for the past five decades. It has developed a four-tier monitoring and computerized surveillance system of the residents of Kaniyambadi block, which is updated monthly. The community health workers, who live within the various village communities, provide the detailed statistics (Joseph et al., 1991). They are supervised by public health nurses and physicians.

\section{Recruitment of participants}

Participants were identified using a computerized list and a door-to-door survey. We invited all elderly people over 65 years of age to participate in this study.

\section{Assessment}

The following instruments were employed to assess the participants: (i) Geriatric Mental State (GMS; Copeland et al., 1986), (ii) Community Screening Instrument for Dementia (CSID; Hall et al., 1993; 2000), (iii) World Health Organization Disability Assessment Scale II (WHODAS II; World Health Organization, 2001), (iv) Modified CERAD 10word list learning task (Ganguli et al., 1996), (v) History and Aetiology Schedule Dementia Diagnosis and subtype (HAS-DDS; Copeland et al., 2002), (vi) Neuropsychiatric Inventory, and (vii) a structured proforma to assess sociodemographic characteristics, medical history and anthropometrics.

\section{Translation of instruments, training of personnel and quality control procedure}

The Tamil versions of the GMS (Rajkumar et al., 1997) and WHODAS II (World Health Organization, 2001) have been employed in earlier studies. The translation of the other instruments followed standard procedure. The training of research staff, data collection and quality control procedures were in accordance with 10/66 norms for population-based studies (Prince et al., 2003). The Institutional Review Board of Christian Medical College, Vellore, approved the study.

\section{Data analysis}

We initially analyzed the socio-demographic data, medical history, psychopathology, cognitive profile and the disability status using descriptive statistics. We derived the psychiatric diagnoses based on the computerized algorithms developed by the 10/66 Dementia Research Group (Prince et al., 2003). We converted the continuous exposure variables to categorical measures by splitting them into two categories using their median values (Ragin, 1994). We calculated the odds ratios with $95 \%$ confidence intervals for various risk factors. We performed multivariate analysis using determinants, which were significant on univariate analysis, employing conditional logistic regression with the statistical software package SPSS 16.0. 


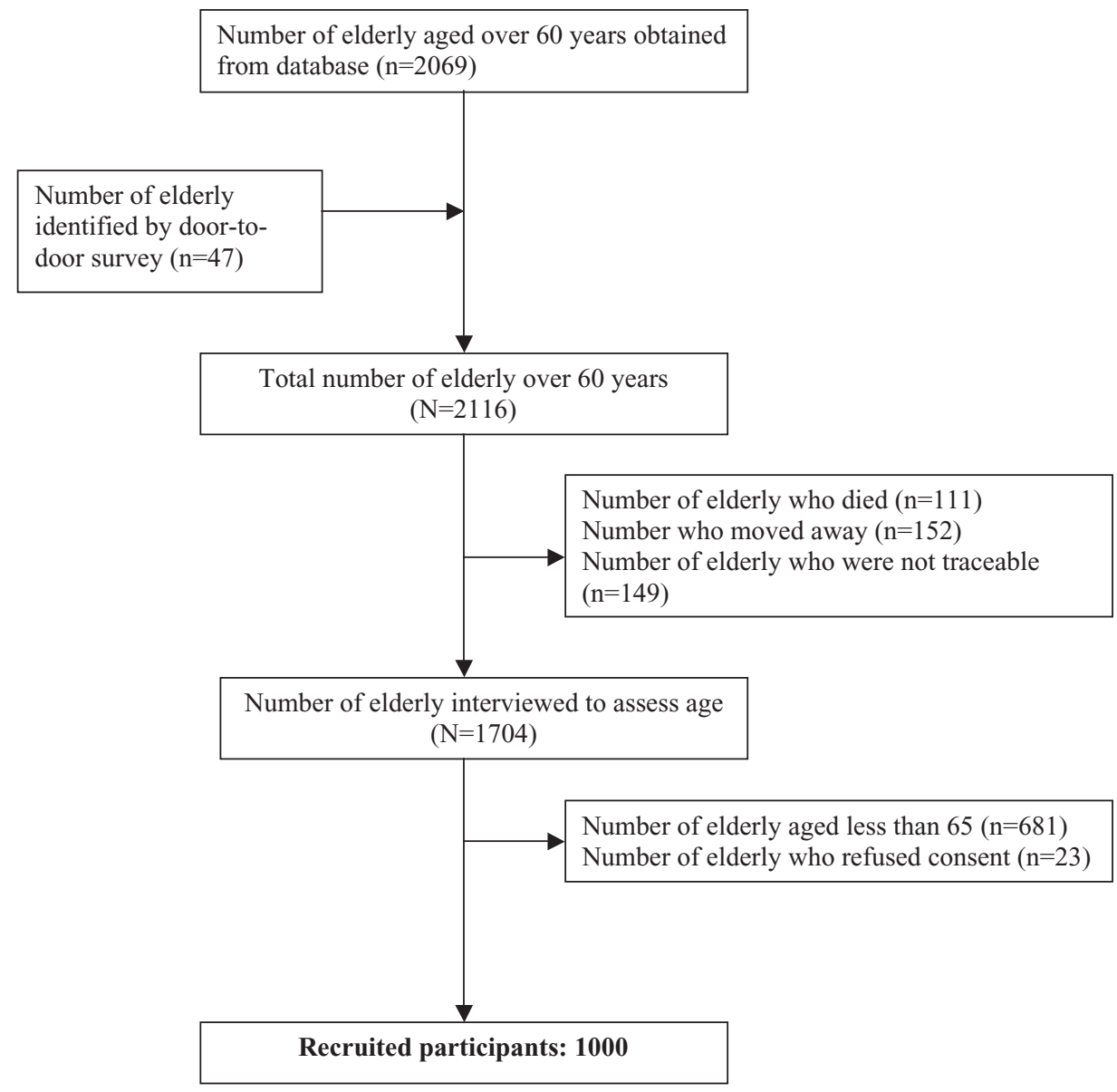

Figure 1. Flowchart of recruitment of participants.

\section{Results}

\section{Participant characteristics}

The details of recruitment of participants are shown in Figure 1. We recruited 1000 participants and the overall response rate was $97.75 \%$. The sociodemographic, psychiatric and disability profiles of the participants are shown in Table 1. The majority of the participants were women, lacking formal education, widowed and from the low-income category. The average age of the participants was 72.5 (SD 5.8) years.

\section{Nature and prevalence of geriatric depression}

The prevalence of any ICD-10 (World Health Organization, 1992) depressive episode in our sample was $12.7 \%$ (95\% CI 10.64-14.76 \%). Among those 127 participants who had geriatric depression, 32 had a mild depressive episode $(3.2 \%$; 95\% CI $2.11-4.29 \%)$, 76 had a moderate depressive episode $(7.6 \%$; 95\% CI 5.96-9.24\%), and 19 had a severe depressive episode $(1.9 \%$; $95 \%$ CI $1.05-2.75 \%)$. The prevalence of major depression according to DSM-IV (American Psychiatric
Association, 1994) criteria was 5.2\% (95\% CI 3.826.58). The prevalence of suicidal ideation within the previous month was $2.1 \%$ (95\% CI 1.21-2.99). The prevalence of dementia defined by DSM-IV was $0.8 \%$ and by the education-adjusted 1066 criteria was $10.6 \%$.

\section{Correlates of geriatric depression}

The correlates of geriatric depression are shown in Table 2. Low income, experiencing hunger within the previous one month, having diabetes, cardiac illnesses, transient ischemic attacks and head injury were correlated with geriatric depression after adjustment for the effects of age, gender, education and the other determinants using conditional logistic regression analysis. Having more confidants had a significant protective effect for depressive disorders. Female gender, age, hypertension, cognitive impairment and more disability were not significantly correlated with geriatric depression.

When we ascertained major depression according to the DSM-IV criteria, the following variables were significantly associated with geriatric 
Table 1. Socio-demographic and psychosocial profiles of the participants $(n=1000)$

\begin{tabular}{|c|c|c|}
\hline VAR I A B LE & SAMPLE N (\%) & MEAN (S D) \\
\hline \multicolumn{3}{|l|}{ Gender: } \\
\hline Male & $454(45.4)$ & \\
\hline Female & $546(54.6)$ & \\
\hline Age in years & & $72.54(5.87)$ \\
\hline \multicolumn{3}{|l|}{ Education: } \\
\hline No formal education & $661(66.1)$ & \\
\hline Primary school dropouts & $195(19.5)$ & \\
\hline Completed primary school & $116(11.6)$ & \\
\hline Secondary education & $26(2.6)$ & \\
\hline Graduate & $2(0.2)$ & \\
\hline \multicolumn{3}{|l|}{ Highest Job status: } \\
\hline agricultural labourer & $768(76.8)$ & \\
\hline Others & $232(23.2)$ & \\
\hline \multicolumn{3}{|l|}{ Marital Status: } \\
\hline Never married & $5(0.5)$ & \\
\hline Married & $481(48.1)$ & \\
\hline Widowed/separated & $514(51.4)$ & \\
\hline Monthly family income (in Indian Rs.) & & $1522(1513)$ \\
\hline Having private/state health insurance & $0(0)$ & \\
\hline Lifetime smoker & $530(53.0)$ & \\
\hline Lifetime alcohol use & $194(19.4)$ & \\
\hline Past history of depression & $22(2.2)$ & \\
\hline Mild cognitive impairment & $37(3.7)$ & \\
\hline Dementia (DSM-IV) & $8(0.8)$ & \\
\hline WHODAS total score & & $28.26(18.27)$ \\
\hline
\end{tabular}

depression after adjustment for the effects of age, gender, education and the other determinants using conditional logistic regression analysis: experiencing hunger within the previous month (OR 2.55; 95\% CI 1.24-5.24); diabetes (OR 4.15; $95 \%$ CI 1.47-11.73); transient ischemic attacks (OR 3.23; 95\% CI 1.31-7.96); past head injury (OR 3.69; 95\% CI 1.42-9.55); mid-arm circumference less than $24 \mathrm{~cm}$ (OR 4.52; 95\% CI 1.72-11.89); and more disability (OR 4.36; 95\% CI 1.94-9.81). Having more confidants (OR 0.12; 95\% CI 0.040.41) was protective.

The significant correlates for recent suicidal ideation, adjusting for age, education and gender using multivariate logistic regression were: being depressed (OR 4.35; 95\% CI 1.75-10.78); experiencing hunger within the previous one month (OR 2.71; 95\% CI 1.06-6.92); average monthly income of the family less than Rs. 1100 (OR $2.84 ; 95 \%$ CI 1.01-8.00). The significant correlates for more functional disability charcterized by WHODAS II total score more than 25, adjusting for age, education and gender using multivariate logistic regression were: being demented (OR 2.84; 95\% CI 1.78-4.53); transient ischemic attacks (OR 4.73; 95\% CI 2.18-10.26); hard of hearing (OR 2.23 ; $95 \%$ CI 1.67-2.97); age above 71 years
(OR 1.97; 95\% CI 1.52-2.56); decreased vision (OR 1.75; 95\% CI 1.27-2.40); female gender (OR $1.62 ; 95 \%$ CI 1.19-2.20); lack of formal education (OR 1.52; 95\% CI 1.09-2.12); experiencing hunger (OR 1.51; 95\% CI 1.04-2.20). A severe depressive episode was not significantly associated with more functional disability (OR 1.10; 95\% CI 0.43-2.81).

\section{Discussion}

This study examined the factors associated with depression among the elderly in a rural south Indian community. Its strengths include a low refusal rate, adequate sample size and ascertaining depression with a standardized diagnostic interview. The possibility of selection bias was avoided by recruiting all consecutive elderly people and by the low refusal rate. We attempted to minimize the recall bias by collaborating with local community health workers and by using a detailed and structured interview. Its limitation was its cross-sectional design and consequent temporal ambiguity.

Physical illnesses and poverty were significantly correlated with geriatric depression, as in other studies (Cole and Dendukuri, 2003; Osborn et al., 2003; Sherina et al., 2004; Tsai et al., 2005; Chi 
Table 2. Factors associated with depression in the elderly

\begin{tabular}{|c|c|c|c|c|c|c|}
\hline \multirow[b]{2}{*}{ VA R I A B L E } & \multirow{2}{*}{$\begin{array}{l}\text { DEPRESSION } \\
\text { PRESENT } \\
(\mathrm{N}=127) \\
\mathrm{N}(\%)\end{array}$} & \multirow{2}{*}{$\begin{array}{l}\text { DEPRESSION } \\
\text { A B S ENT } \\
(\mathrm{N}=873) \\
\mathrm{N}(\%)\end{array}$} & \multicolumn{2}{|c|}{ BIVARIATE STATISTICS } & \multicolumn{2}{|c|}{ MULTIVARIATE STATISTIC ${ }^{a}$} \\
\hline & & & $\begin{array}{l}\text { ODDS } \\
\left(\begin{array}{ll}95 \% & \text { CITIO }\end{array}\right.\end{array}$ & P-VALUE & $\begin{array}{l}\text { ODDS } \\
\left(\begin{array}{ll}95 \% & \text { CI }\end{array}\right)\end{array}$ & P-VALUE \\
\hline Female gender & $67(52.8)$ & $479(54.9)$ & $0.92(0.63-1.33)$ & 0.66 & $0.63(0.38-1.04)$ & 0.07 \\
\hline Age above 71 years & $69(54.3)$ & $471(54.0)$ & $1.02(0.70-1.48)$ & 0.94 & $0.95(0.61-1.46)$ & 0.80 \\
\hline Illiteracy & $92(72.4)$ & $569(65.2)$ & $1.40(0.93-2.12)$ & 0.11 & $1.21(0.69-2.13)$ & 0.51 \\
\hline Monthly family income below Rs.1100 & $88(69.3)$ & $417(47.8)$ & $2.47(1.65-3.68)$ & 0.000 & $1.78(1.08-2.91)$ & 0.02 \\
\hline Experienced hunger within past 30 days & $45(35.4)$ & $96(11.0)$ & $4.44(2.92-6.77)$ & 0.000 & $2.58(1.56-4.26)$ & 0.000 \\
\hline Widowed/separated status & $68(53.5)$ & $446(51.1)$ & $1.10(0.76-1.60)$ & 0.61 & $0.95(0.53-1.69)$ & 0.85 \\
\hline Living alone & $23(18.1)$ & $97(11.1)$ & $1.77(1.08-2.91)$ & 0.03 & $1.43(0.78-2.61)$ & 0.25 \\
\hline Living within five miles of siblings & $59(46.5)$ & $535(61.3)$ & $0.55(0.38-0.80)$ & 0.002 & $0.75(0.49-1.15)$ & 0.19 \\
\hline Having four or more confidants & $8(6.3)$ & $384(44.0)$ & $0.09(0.04-0.18)$ & 0.000 & $0.13(0.06-0.26)$ & 0.000 \\
\hline No regular physical exercise ${ }^{b}$ & $78(61.4)$ & $432(49.5)$ & $1.63(1.11-2.38)$ & 0.01 & $1.14(0.73-1.79)$ & 0.56 \\
\hline History of hypertension & $18(14.2)$ & $108(12.4)$ & $1.17(0.68-2.00)$ & 0.57 & $1.10(0.56-2.14)$ & 0.79 \\
\hline History of Diabetes mellitus & $16(12.6)$ & $50(5.7)$ & $2.37(1.31-4.31)$ & 0.005 & $2.33(1.15-4.72)$ & 0.02 \\
\hline History of TB within the past five years & $10(7.9)$ & $29(3.3)$ & $2.49(1.18-5.24)$ & 0.02 & $1.34(0.55-3.26)$ & 0.52 \\
\hline History of transient ischemic attack & $18(14.2)$ & $26(3.0)$ & $5.37(2.85-10.12)$ & 0.000 & $2.43(1.17-5.05)$ & 0.02 \\
\hline History of cardiac illnesses & $12(9.4)$ & $16(1.8)$ & $5.59(2.58-12.11)$ & 0.000 & $4.75(1.96-11.52)$ & 0.001 \\
\hline History of head injury with LOC & $19(15.0)$ & $33(3.8)$ & $4.48(2.46-8.15)$ & 0.000 & $2.70(1.36-5.36)$ & 0.005 \\
\hline Hearing impairment & $50(39.4)$ & $264(30.2)$ & $1.50(1.02-2.20)$ & 0.04 & $1.46(0.93-2.28)$ & 0.10 \\
\hline Mid-arm circumference less than $24 \mathrm{~cm}$ & $89(70.1)$ & $514(58.9)$ & $1.64(1.09-2.45)$ & 0.02 & $1.24(0.78-1.97)$ & 0.37 \\
\hline Mild cognitive impairment & $2(1.6)$ & $35(4.0)$ & $0.38(0.09-1.61)$ & 0.19 & $0.49(0.10-2.29)$ & 0.36 \\
\hline Dementia $^{c}$ & $2(1.6)$ & $6(0.7)$ & $2.31(0.46-11.58)$ & 0.31 & $0.34(0.05-2.27)$ & 0.27 \\
\hline WHODAS total score more than 25 & $53(41.7)$ & $412(47.2)$ & $0.80(0.55-1.17)$ & 0.25 & $0.68(0.42-1.11)$ & 0.13 \\
\hline
\end{tabular}

a Adjusted odds ratios calculated using conditional logistic regression. The following variables were included in the conditional logistic regression analysis: age, gender, education, low income,

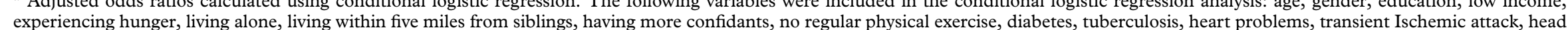
injury, hearing impairment and smaller mid-arm circumference.

$\mathrm{b}$ Walking for at least 500 meters less than six times per week.

c Diagnosis based on DSM-IV criteria.

LOC $=$ loss of consciousness. 
et al., 2005; Khattri and Nepal, 2006; Jain and Aras, 2007; Kaneko et al., 2007). However, female gender, advancing age and cognitive impairment were not associated with geriatric depression. More surprisingly, depressive disorders did not indicate more functional disability in this population. The depressed individuals in low-income communities rarely subscribe to biomedical causal models and hold more to psychosocial as well as interpersonal explanatory models for depression (Pereira et al., 2007). Such explanatory models may mitigate perceived stigma (Raguram et al., 1996). The meager expectations by families of their elderly relatives may also contribute towards high tolerance of depressive symptoms and functional impairment (Jacob et al., 2007b).

Elderly people report depressive symptoms when they are distressed, when they are ill or are worried about the implication of their symptoms. Stressful life events and inability to cope with psychosocial problems may also lead the elderly to mention such symptoms. Consequently, the difficulty in separating distress from depression becomes a major issue (Heath, 1999). While psychiatrists suggest that brief screening instruments can easily identify people with depression (Kessler et al., 1999), most general practitioners (GPs) would argue that many of those identified are distressed (Heath, 1999). The depression seen in the community and which many GPs encounter is often viewed as a result of personal and social stress, life style choices or as a product of habitual maladaptive patterns of behavior. Consequently, the general population and primary care physicians often hold psychological and social models for depression (Jacob, 2006). Psychiatrists, with their biomedical frameworks, would on the other hand argue for disease models (Kessler et al., 1999). The relationship between poverty, social isolation, physical health and mental health is complex (Kuruvilla and Jacob, 2007). However, the cross-sectional and observational nature of this study mandates the need for cohort designs to confirm associations and randomized trials to assess intervention.

\section{Conflict of interest}

None.

\section{Description of authors' roles}

K. S. Jacob and M. Prince designed the study and supervised data collection and analysis. P. Senthilkumar and K. Gayathri collected the data and assisted with writing the paper. A.P. Rajkumar,
P. Thangadurai and K. S. Jacob analyzed the data and wrote the paper.

\section{Acknowledgments}

This study is part of the population-based investigations of the 10/66 Dementia Research Group of Alzheimer's Disease International. It was supported by grants from the World Health Organization and the Institute of Psychiatry, London. We thank all the study participants as well as their families and the community health workers for their cooperation, and the research fellows Ms. A. Kanagathara and Ms. C. Symon for data collection.

\section{References}

American Psychiatric Association (1994). Diagnostic and Statistical Manual of Mental Disorders, 4th edn (DSM- IV). Washington, DC: American Psychiatric Association.

Arthur, A., Jagger, C., Lindesay, J., Graham, C. and Clarke, M. (1999). Using an annual over-75 health check to screen for depression: validation of the short Geriatric Depression Scale (GDS15) within general practice. International fournal of Geriatric Psychiatry, 14, 431-439.

Chi, I. et al. (2005). Prevalence of depression and its correlates in Hong Kong's Chinese older adults. American fournal of Geriatric Psychiatry, 13, 409-416.

Cole, M. G. and Dendukuri, N. (2003) Risk factors for depression among elderly community subjects: a systematic review and meta-analysis. American fournal of Psychiatry, 160, 1147-1156.

Copeland, J. R., Dewey, M. E. and Griffith- Jones, H. M. (1986). A computerized psychiatric diagnostic system and case nomenclature for elderly subjects: GMS and AGECAT. Psychological Medicine, 16, 89-99.

Copeland, J. R., Prince, M., Wilson, K. C., Dewey, M. E., Payne, J. and Gurland, B. (2002). The Geriatric Mental State examination in the 21 st century. International Fournal of Geriatric Psychiatry, 17, 727-732

Ganguli, M. et al. (1996). Cognitive test performance in a community-based nondemented elderly sample in rural India: the Indo-U.S. Cross-National Dementia Epidemiology Study. International Psychogeriatrics, 8, 507-524

Ganguli, M., Dube, S., Johnston, J. M., Pandav, R., Chandra, V. and Dodge, H. H. (1999). Depressive symptoms, cognitive impairment and functional impairment in a rural elderly population in India: a Hindi version of the geriatric depression scale (GDS-H). International Fournal of Geriatric Psychiatry, 14, 807-820.

Hall, K. S., Hendrie, H. C. and Brittain, H. M. (1993). The development of a dementia-screening interview in two distinct languages. International fournal of Methods in Psychiatric Research, 3, 1-28.

Hall, K. S., Gao, S., Emsley, C. L., Ogunniyi, A. O., Morgan, O. and Hendrie, H. C. (2000). Community 
screening interview for dementia (CSI 'D'): performance in five disparate study sites. International fournal of Geriatric Psychiatry, 15, 521-531.

Heath, I. (1999). Commentary: there must be limits to the medicalisation of human distress. BMF, 318, 439-440.

Jacob, K. S. (2006). The cultures of depression. National Medical fournal of India, 19, 218-220.

Jacob, K. S., Senthil Kumar, P., Gayathri, K., Abraham, S. and Prince, M. J. (2007a). The diagnosis of dementia in the community. International Psychogeriatrics, 19, 669-678.

Jacob, K. S., Senthil Kumar, P., Gayathri, K., Abraham, S. and Prince, M. J. (2007b) Can health workers diagnose dementia in the community? Acta Psychiatrica Scandinavica, 116, 125-128.

Jain, R. K. and Aras, R. Y. (2007). Depression in geriatric population in urban slums of Mumbai. Indian fournal of Public Health, 51, 112-113.

Jhingan, H. P., Sagar, R. and Pandey, R. M. (2001). Prognosis of late-onset depression in the elderly: a study from India. International Psychogeriatrics, 13, 51-61.

Jongenelis, K., Pot, A. M., Eisses, A. M., Beekman, A. T., Kluiter, H. and Ribbe, M. W. (2004). Prevalence and risk indicators of depression in elderly nursing home patients: the AGED study. Fournal of Affective Disorders, 83, 135-142.

Joseph, A., Joseph, K. S. and Kamaraj, K. (1991). Use of computers in primary health care. International fournal of Health Sciences, 2, 93-101.

Kaneko, Y., Motohashi, Y., Sasaki, H. and Yamaji, M. (2007). Prevalence of depressive symptoms and related risk factors for depressive symptoms among elderly persons living in a rural Japanese community: a cross-sectional study. Community Mental Health fournal, 43, 583590.

Kessler, D., Lloyd, K., Lewis, G. and Gray, D. P. (1999). Cross sectional study of symptom attribution and recognition of depression and anxiety in primary care. BMF, 318, 436-439.

Khattri, J. B. and Nepal, M. K. (2006). Study of depression among geriatric population in Nepal. Nepal Medical College fournal, 8, 220-223.

Kørner, A. et al. (2007). Rating scales for depression in the elderly: external and internal validity. Fournal of Clinical Psychiatry, 68, 384-389.

Kuruvilla, A. and Jacob, K. S. (2007). Poverty, social stress and mental health. Indian fournal of Medical Research, 126, 273-278.
McGivney, S. A., Mulvihill, M. and Taylor, B. (1994). Validating the GDS depression screen in the nursing home. Fournal of the American Geriatrics Society, 42, 490-492.

Mitchell, A. J. and Subramaniam, H. (2005). Prognosis of depression in old age compared to middle age: a systematic review of comparative studies. American fournal of Psychiatry, 162, 1588-1601.

Osborn, D. P. et al. (2003). Factors associated with depression in a representative sample of 14,217 people aged 75 and over in the United Kingdom: results from the MRC trial of assessment and management of older people in the community. International fournal of Geriatric Psychiatry, 18, 623-630.

Pereira, B., Andrew, G., Pednekar, S., Pai, R., Pelto, P. and Patel, V. (2007). The explanatory models of depression in low-income countries: listening to women in India. Fournal of Affective Disorders, 102, 209-218.

Prince, M. J., Acosta, D., Chiu, H., Scazufca, M. and Varghese, M. (2003). Dementia diagnosis in developing countries: a cross-cultural validation study. Lancet, 361, 909-917.

Ragin, C. (1994). Constructing Social Research. Thousand Oaks, CA: Pine Forge Press, Sage.

Raguram, R., Weiss, M. G., Channabasavanna, S. M. and Devins, G. M. (1996). Stigma, depression, and somatization in South India. American Fournal of Psychiatry, 153, 1043-1049.

Rajkumar, S., Kumar, S. and Thara, R. (1997). Prevalence of dementia in a rural setting: a report from India. International fournal of Geriatric Psychiatry, 12, 702-707.

Sherina, M. S., Rampal, L. and Mustaqim, A. (2004). The prevalence of depression among the elderly in Sepang, Selangor. Medical Fournal of Malaysia, 59, 45-49.

Steffens, D. C. and Potter, G. G. (2008). Geriatric depression and cognitive impairment. Psychological Medicine, 38, 163-175.

Tsai, Y. F., Yeh, S. H. and Tsai, H. H. (2005). Prevalence and risk factors for depressive symptoms among community-dwelling elders in Taiwan. International fournal of Geriatric Psychiatry, 20, 1097-1102.

van't Veer-Tazelaar, P. J. et al. (2008). Depression in old age (75+): the PIKO study. Fournal of Affective Disorders, 106, 295-299.

World Health Organization (1992) The ICD-10 classification of mental and behavioural disorders: Diagnostic Criteria for Research. Geneva: WHO.

World Health Organization (2001). WHODAS II Disability Assessment Schedule. Geneva: WHO. 